\title{
Understanding powder degradation in metal additive manufacturing to allow the upcycling of recycled powders
}

Daniel Powell ${ }^{a *}$, Allan Rennie ${ }^{\mathrm{a}}$, Louise Geekie ${ }^{\mathrm{b}}$, Neil Burns ${ }^{\mathrm{a}, \mathrm{b}}$

d.powell3@lancaster.ac.uk, a.rennie@lancaster.ac.uk, louise@croftam.co.uk, neil@filters.co.uk

a) Engineering Department, Lancaster University, Lancaster, Lancashire, LA1 4YW, England

b) Croft Additive Manufacturing Ltd, Risley, Warrington, Cheshire, WA3 6BL, England

*Corresponding Author

\section{Abstract}

To ensure the financial viability of powder-based additive manufacturing technologies, the recycling of powders is common practice. This paper shows the lifecycle of metal powder in additive manufacturing, investigating powder manufacture, powder usage, mechanisms of powder degradation and the usage of end-of-life powder. Degradation of powders resulting from repeated reuses was found to be a widespread problem; components produced from heavily reused powders are typically of a lower quality, eventually rendering the powder unusable in additive manufacturing. Powder degradation was found to be dependent on many variables, preventing the identification of a definitive end-of-life point for powders. The most accurate method of determining powder quality was found to be the production and analysis of components using these powders. Uses for degraded powder had not been previously identified in literature, warranting the investigation of potential solutions to prevent powder waste. Amongst other waste-reducing solutions, plasma spheroidisation was identified as a promising method to avoid powder disposal for approximately $12.5 \%$ of produced powders, creating particles similar to virgin powder from end-of-life powder. Returning end-of-life powders to the supplier for upcycling may be the only financially viable solution to reduce waste within the industry. The compilation of research within this paper aims to enable users of additive manufacturing to conduct further research and development into powder upcycling.

Keywords: Additive Manufacturing; Metallurgy; Powder Degradation; Upcycling; Plasma Spheroidisation

Word Count:

Entire document $-14,092$

Minus title, abstract, acknowledgements and reference list $\mathbf{- 1 1 , 8 5 6}$ 


\section{Introduction}

Additive Manufacturing (AM) has seen a significant increase in usage over the past decade (Wohlers et al., 2019). One of the many reasons AM has become widely adopted is the efficiency of the process. From an economic stance, achieving the maximum product output from raw materials yields maximised potential profits. This is where AM excels, using only the material required for the manufacture of the product, alongside any necessary support structures and heat sinks. Through $\mathrm{AM}$, material usage can be reduced by up to $40 \%$ versus conventional subtractive machining methods (Reeves, 2008; cited in The Economist, 2011).

The polymer materials initially used to create prototypes within the AM industry were ideal for rapid accurate production and easy utility. However, as AM has been increasingly considered for the manufacture of high-quality end-use products, such as within the aerospace industry, polymers rarely meet the design needs. This encouraged the development of several metal AM processes, designed to produce components that are ready-for-market. The revenue from metals has seen a continual growth of over $40 \%$ since 2014 , indicating the increasing adoption of AM for production applications (Wohlers et al., 2019). Of the seven recognised AM processes defined by the American Society for Testing and Materials (ASTM) (ASTM Standard 52900, 2015), there are three main categories that utilise metal powders: Powder-Bed Fusion, Directed Energy Deposition and Binder Jetting.

Powder Bed Fusion (PBF) targets either a laser or electron beam on a flattened "bed" of metal powder, fusing particles together by melting them. Once a layer has been formed, the powder bed drops down by a predetermined layer thickness. More powder is added to the build chamber and distributed as an even layer using a spreading mechanism. The laser or electron beam then melts this new layer, fusing with the previously melted layer beneath. This is repeated until the build is complete. Through this process, detailed parts can be manufactured to a high standard. Metallic PBF processes include Selective Laser Melting (SLM), Electron Beam Melting (EBM) and Direct Metal Laser Sintering (DMLS). PBF machines make up 54\% of the technologies available on the metal AM market (Cherdo, 2019).

Directed Energy Deposition (DED) directs a constant stream of powder metal feedstock from a nozzle (although wire can be used) onto the surface of an already constructed object. This feedstock is melted by a laser or electron beam, depositing metal onto the surface where the laser is focused. The object remains stationary, whilst the nozzle can move freely, allowing material to be added anywhere on the object. Typically, DED is used for the repair or maintenance of large components, owing to a poorer finish quality, although it can be used to build new components. As there is less demand for this application, DED machines account for $16 \%$ of all machines available in the metal AM market (Cherdo, 2019).

Binder Jetting (BJ) utilises a liquid binder to adhere layers of metal powder together. Alternating layers of powder and binder are deposited, releasing binder only where adhesion is necessary. As in PBF, once one layer of powder and binder has been deposited, the build platform is lowered by a set layer thickness and the process repeats until the component is fully built. BJ components lack the part accuracy and mechanical properties of their PBF counterparts so are less common in the metal AM industry, accounting for $16 \%$ of machines on the AM market (Cherdo, 2019).

Whilst the above processes are additive and considered to be "clean", producing little-to-no waste (Bourhis et al., 2014; Campbell et al., 2011), there are problems associated with powder-based AM systems that reduce the material efficiency of the process. In PBF and BJ, it is not possible to produce a $1 \mathrm{~cm}^{3}$ component from $1 \mathrm{~cm}^{3}$ of metal powder, as the powder bed requires a minimum 
volume of powder dependent on the build chamber size, regardless of the desired component's size. This often results in a very small percentage of powder being used. In DED, as little as $50.2 \%$ of the powder feedstock is utilised and added to the component (Takemura et al., 2019), with the remaining powder being dispersed into the build chamber.

A widely adopted practice is to recycle any unused powder and use it in future builds. Reeves (2008; cited in The Economist, 2011) believed that the recycle rates of powder are between $90-95 \%$, whilst Petrovic et al. (2010) suggest that between $95-98 \%$ of powder not used in the build can be reused. There are a number of benefits to reusing metal powders. A range of metals are used to build with in AM, including Ti6Al4V, Inconel 718, AISi10Mg, 316L stainless steel and 304L stainless steel, varying in cost from $£ 30$ to $£ 300$ or more per kilogram of virgin powder (Ian Brooks 2019, personal communication). As material cost can make up $31 \%$ of the cost of the entire build (Piller et al., 2018), recycling this metal powder has significant economic benefits to AM users. This was shown in a case study by LPW Technology Ltd, seeing a 92\% reduction in material costs if a powder was reused 15 times (Rushton, 2019).

Steps need to be taken to ensure any reused powder remains of an acceptable quality for use in AM. This typically means ensuring the powder properties are as similar as possible to the virgin powder produced by the supplier. To ensure this happens, well-established powder handling procedures are employed. The powder is kept in an inert environment during building and whilst in storage to prevent oxidisation and wetting, with minimal exposure to the air. Any powder that was not incorporated into the component is collected from the build chamber and sieved using one of a number of techniques, removing any oversized particles or other debris resulting from the fabrication process. Strict cleaning regulations of equipment are maintained to prevent potential contamination of the powder. This process is not currently regulated by any standards and is based on user experience, causing a great deal of variation throughout the industry (Leicht, 2018).

Reducing the quantity of unused "virgin" powder manufactured is also beneficial for the environment. The production of the metal powder uses a process called atomisation. Faludi et al. (2016) found that the energy consumption during gas atomisation of an aluminium alloy used to produce one part could be up to $24.5 \%$ of the energy consumption used in the PBF manufacturing process from start to finish, gram for gram. With repeated reuse of the powder, the impact of the production of metal powders reduces.

The rapidly developing AM industry has carried out research into the consequence of continually reusing metal powder in AM. The production, usage and recycling of metal powders are identified as issues in AM and 'require more attention' (Javidrad et al., 2018). Research into the effect of recycling metal powders in AM is collected and analysed within this paper, complimented by investigation into the mechanisms through which powder degrades. This paper aims to provide a foundation upon which further research can be out, identifying strategies to improve the longevity and traceability of metal powders and reduce waste in the AM industry.

\section{Methodology for selecting literature}

It is difficult to narrow down a literature review to any one material, as there would not be a wide enough range of data available. Furthermore, it would limit the application of this review to one material, throttling the impact of this work on the wider AM community. The literature reviewed therefore includes a wide variety of metallic powders. Comments are made when necessary if any findings are notably different as a result of the material. 
Exclusively searching for sources on PBF would further bottleneck the impact of this research, as the problems identified in powder recycling are suffered by all powder-based AM users. By considering the research of the three previously identified metal AM processes, a broader understanding of the problem is given. Further to this, these sources may offer potential solutions that may not have been identified in a restricted literature review. However, an emphasis is placed upon PBF, as this is the most common metallic AM process (Cherdo, 2019).

Work of a similar nature had been undertaken by Vock et al. (2019), reviewing powder properties and touching upon the impact of recycling on these properties. As such, their work offered a starting point for the collection of literature. However, their review does not provide a detailed analysis of each study, nor does it offer understanding as to why observed changes had taken place. Their review instead aimed to identify processes to qualify powder, whilst the work within aims to promote understanding of the methods through which powder degrades, ultimately intending to identify methods to upcycle degraded powders.

\section{Literature Review}

The background research has been separated into sections, building from a micro to macro level, as properties at the individual particle level can influence the overall powder behaviour, in turn influencing the final built component. This is represented in Figure 1; many individual particles make up a powder, with even more particles fusing to form a component. Section 3.1 gives a brief overview of the methods of powder production used within the AM industry. Section 3.2 investigates the individual powder particle properties that are determined from the powder production phase, considering how these interact with one another to influence powder properties. The impact of the changes due to recycling powder on built components is reviewed in Section 3.3. Section 3.4 looks at literature that has used a mixture of virgin and recycled powder. Consideration is then given to end-of-life (EoL) powder and the current common practices for the disposal or reuse of this powder in Section 3.5.

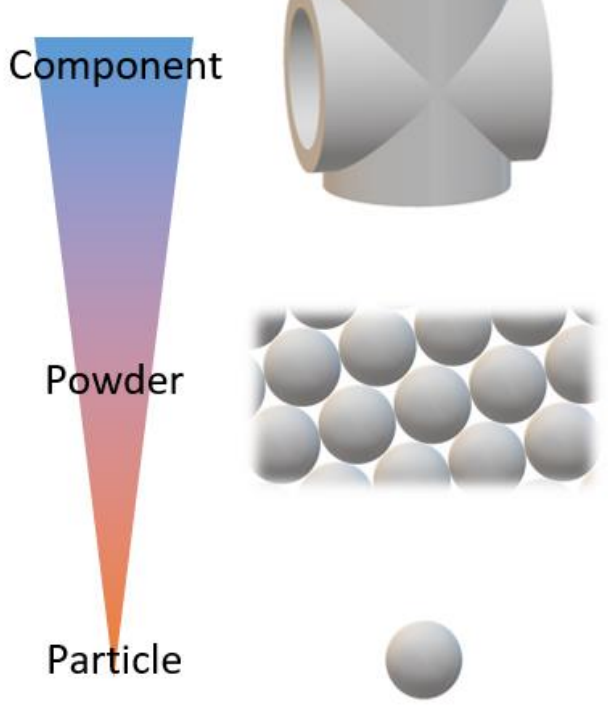

Figure 1 - Representation of the increasing number of particles present, from an individual particle through to component 


\subsection{Methods of powder production}

Before the AM process can begin, powder feedstock needs to be created. This is done through a process called atomisation, identified as the best way to form metal powders for use in AM (Dawes et al., 2015). As is the case in all manufacturing procedures, the quality of the material feedstock will affect the quality of a produced component. Investigation into the atomisation process enables understanding of the quality of virgin powder available for use in AM. Although several types of atomisation exist, there are three preferred methods within the AM industry that are to be focused on: water atomisation, gas atomisation and plasma atomisation.

All three procedures operate on similar principles. The metal feedstock is melted prior to being fed into an atomisation chamber, where it is blasted by jets of either water, gas or plasma, resulting in the rapid dispersion and solidification of the metal into small particles. Each process is discussed below. Section 3.2 provides further context to why some methods are considered preferable.

Powder produced through water atomisation is typically highly irregular in morphology, making it less preferable for use in the AM industry (Irrinki et al., 2016; Dawes et al., 2015). A further disadvantage of water atomisation was identified by Li et al. (2010) and Herzog et al. (2016), finding an increased oxygen content in water atomised powders versus gas atomised powders. Water atomised powder also requires post-processing to dry the powder. Despite this, due to the relative simplicity of the procedure, water atomised powder is the cheapest AM suitable powder, making it appealing to some AM users (Dawes et al., 2015).

Gas atomised powder utilises inert gases to reduce the risk of oxidation and contamination of the powder. Due to the lower heat capacity of gases, the particles have longer to cool, allowing spherical particles to form (Dawes et al., 2015). This has been widely accepted to be preferable to water atomisation (Kelkar, 2018; Herzog et al., 2016; Li et al., 2010).

Plasma atomisation uses either wire or powder feedstock that is melted and immediately atomised to minimise any chance of contamination. The particles created by plasma atomisation are highly spherical (Dawes et al., 2015). As powder can be used as a feedstock, this process has been adapted to improve lower quality powders, such as those produced by the cheap water atomisation process. This has been successfully demonstrated by Kelkar (2018). However, the plasma atomisation process is more expensive than water or gas atomisation and is therefore typically only used to produce very high-quality powders (Dawes et al., 2015).

Morrow et al. (2007) showed that the direct atomisation of tool steel consumed 17.62MJ per kilogram of powder produced from raw materials. If a steel plate were to be created and then remelted for use in the atomisation process, $32.81 \mathrm{MJ}$ of energy would be consumed per kilogram of powder produced, using $86.2 \%$ more energy than direct atomisation. This provides a benchmark for energy usage against which future solutions can be compared. If a method of reclaiming powder consumes less energy than the atomisation process, the environmental benefit is twofold; less powder is sent to landfill, whilst less energy is used to produce new virgin powder for use in AM.

If alternative powder feedstocks can be identified for use in the atomisation process, the energy consumption in the AM cycle may be further reduced. Morrow et al. (2007) showed that 6.25MJ is required to remelt one kilogram of steel, whilst only $1 \mathrm{MJ}$ is required to atomise this melted steel into one kilogram of powder. Therefore, producing powder from already-produced steel only requires $41.1 \%$ of the energy used in creating powder from direct atomisation, indicating that scrap metals could provide a far more sustainable feedstock material than raw materials in the atomisation process. 


\subsection{Particle and powder properties}

Through the gas atomisation process, powder particles tens of microns in diameter are produced. There are up to 1 billion particles in one kilogram of powder (Harrison, 2019). Each of these particles will vary in size, shape and often slightly in chemical composition. It is accepted that the properties of these particles have a large influence on the quality of the powder and the properties of the manufactured component (Vock et al., 2019; Sames et al, 2016). These are further discussed in Section 3.3.

Only literature that reuses powder repeatedly (without mixing in any virgin powder) is reviewed here, allowing the impact of powder recycling on each of these properties to be analysed in a worstcase scenario. The practice of mixing virgin and recycled powder is discussed in Section 3.4.

\subsubsection{Particle size distribution}

The Particle Size Distribution (PSD) is a measure of the frequency of various sized particles within a powder, commonly represented by a cumulative frequency diagram or a histogram. Wider PSD ranges allow for more closely packed particles (explained in Section 3.2.2). As such, PSD graphs can be indicative of powder properties and behaviour, as the particle interactions can influence bulk powder properties.

In order to measure the PSD, particles are assumed to be perfectly spherical. This allows the diameter of each particle to represent their overall 3-dimensional size. The graphs produced are often complimented by the mean, $\mathrm{d} 10, \mathrm{~d} 50$ and $\mathrm{d} 90$ values. The $\mathrm{d} 10$ value marks the point where $10 \%$ of particles in the powder are below this size. The $d 50$ and $d 90$ values are similar, with $50 \%$ and $90 \%$ of particles being smaller than this value respectively. This allows for a quick understanding of the makeup of the powder, enabling users to determine the suitability of a powder for an application.

Powder reuse within PBF has been shown to have various effects on the PSD of powder. Slotwinski et al. (2014) compared eight 316L stainless steel powders after repeated reuse in SLM using an $80 \mu \mathrm{m}$ sieve, seeing a gradual increase in the $\mathrm{d} 10, \mathrm{~d} 50$ and $\mathrm{d} 90$ values with powder recycling. Sartin et al. (2017) found a statistical difference after reusing 316L stainless steel powder seven times in SLM with an $80 \mu \mathrm{m}$ sieve, with an increase in the presence of particles over $45 \mu \mathrm{m}$. A shift towards larger particles in SLM was also observed by Ardila et al. (2014) using Inconel 718 and a $63 \mu \mathrm{m}$ sieve, although there seemed to be very little change in the first seven builds from virgin powder. The notable change was instead observed between the seventh and fourteenth reuse of the powder. A comparison on EBM and SLM PSDs in the same study showed that recycling powder in the SLM process caused the PSD to increase, whilst in EBM the reverse occurred. This is most likely due to the recycled EBM powder having been treated by blasting to break the bonds between particles, a common practice with EBM powders, whilst the SLM powder was only sieved. Ti-6Al-4V was observed by Seyda et al. (2012) to shift in PSD, with fewer small particles present after six powder use cycles passing through an $80 \mu \mathrm{m}$ sieve. This trend continued after 12 cycles, showing a slow but steady increase in the percentage of large particles present in the powder. A white paper produced in 2016 by Renishaw plc, one of the leading manufacturers of AM systems, showed a very slight increase in the $d 10, d 50$ and $d 90$ values of a Ti6Al4V powder recycled 38 times with sieving. The absence of smaller particles was also observed in images obtained from a Scanning Electron Microscope (SEM). The increase in particle size was, however, smaller than other literature found.

Similar results have also been observed in DED processes. Renderos et al. (2016) observed an immediate change in PSD after just one use of Inconel 718 virgin powder passed through a $150 \mu \mathrm{m}$ 
sieve, with considerably fewer small particles present. The trend of an increase in average particle size then continued with powder reuse.

Not every research group offered an explantion for the change in PSD. Slotwinski et al. (2014) believed the cause for the change was the formation of agglomerate particles (discussed in Section 3.2.3). Seyda et al. (2012) agreed that a high proportion of fine particles gives rise to agglomeration effects, but also hypothesised that small particles can be more easily thrown into the air during sieving and powder handling. Small particles vaporising from the laser during the build process could be another cause for the reduction in the number of small particles (Carroll et al., 2006; Gasper et al., 2018). Strondl et al. (2015) suggested two potential explanations for a reduction in small particles. It is possible that the smallest particles could be blown away and become trapped in filters by the inert gas stream during processing. Alternatively, the largest particles may be swept out the build chamber by the recoating arm, causing a higher volume of small particles to be used, whilst the larger particles are repeatedly unused. The latter hypothesis has been suggested by others (Slotwinski et al., 2014; Jacob et al., 2017). Spatter particles ejected from the melt pool (further discussed in Section 3.2.4) were shown by Andani et al. (2018) to be larger than virgin powder, but often small enough to pass through a sieve, potentially shifting the PSD towards larger particles.

Not all literature reported an increase in PSD. Carroll et al. (2006) saw a great deal of variance in the mean particle size over ten powder reuses, making it difficult to determine if any significant change occurred with continual powder reuse. Only the mean particle size is measured, giving little information about the powder overall. Petrovic et al. (2015) used a similar blasting process with EBM-based powder as used by Ardila et al. (2014), finding that there was minimal change to the PSD with repeated powder reuse.

\subsubsection{Packing density}

The size of the particles in powder has a major impact on its usability, having been identified as the most important property contributing to the powder layer quality (Karapatis, 2002). Within AM, it is highly undesirable to have each particle the same size. Figure 2 demonstrates how particles pack when they are of a uniform size, leaving numerous unfilled regions. The coverage of the particles over the background can be related to the packing density, as this demonstrates how well particles within a powder can occupy a space. Image analysis using ImageJ (Rasband, 1997-2018) shows that $79.2 \%$ coverage has been achieved. Figure 3 illustrates the packing of a range of particle sizes, capable of filling in many of the regions between larger particles. This achieves $84.6 \%$ coverage, showing the benefit of using a variety of particle sizes. These images represent the problem in 2dimensional space. As powder occupies a 3-dimensional space, the magnitude of this $5.4 \%$ difference in coverage significantly increased when multiple layers of powder particles are considered. Any uncovered region could lead to the formation of pores and reduced component density (see Section 3.3.2). 


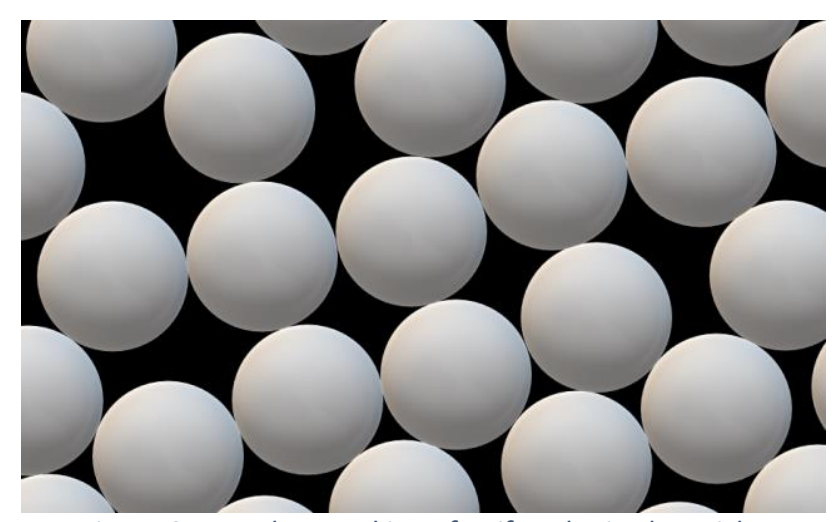

Figure 2-Random packing of uniformly sized particles

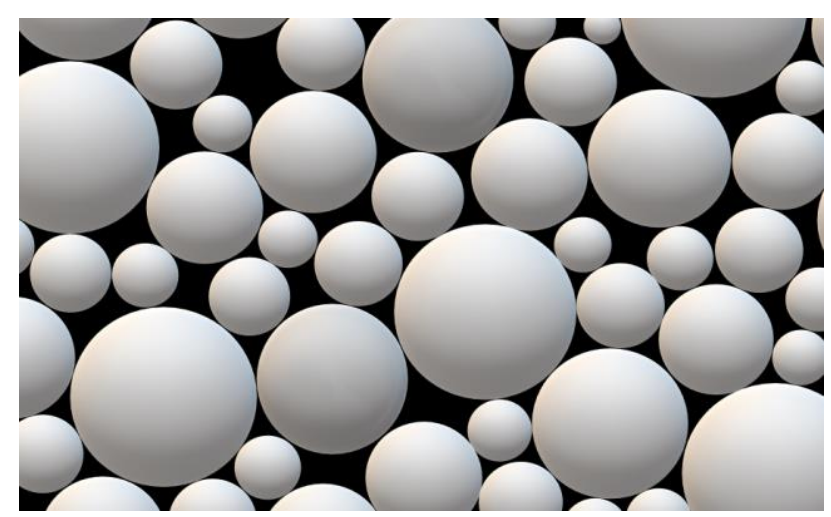

Figure 3-Random packing of various sized particles

The formation of agglomerate particles is discussed in Section 3.2.3. These particles have an impact on the ability of particles to pack closely to one another and occupy space effectively. The principle of this is demonstrated in Figure 4 and Figure 5 . The particles are completely spherical in Figure 4, achieving a coverage of $86.8 \%$. However, when the agglomerate particles are added in Figure 5 , the coverage reduces to $83.9 \%$. Once again, this value of $2.9 \%$ decrease becomes far more significant when a 3-dimensional space is considered.

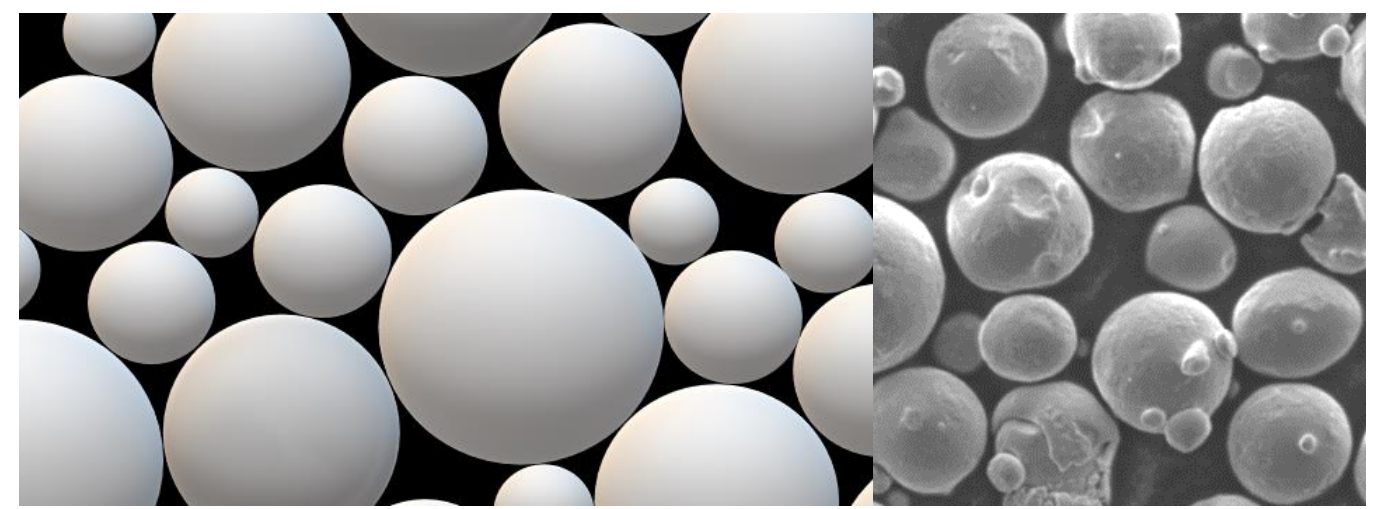

Figure 4-Distribution of spherical particles (Left: model. Right: SEM image) 


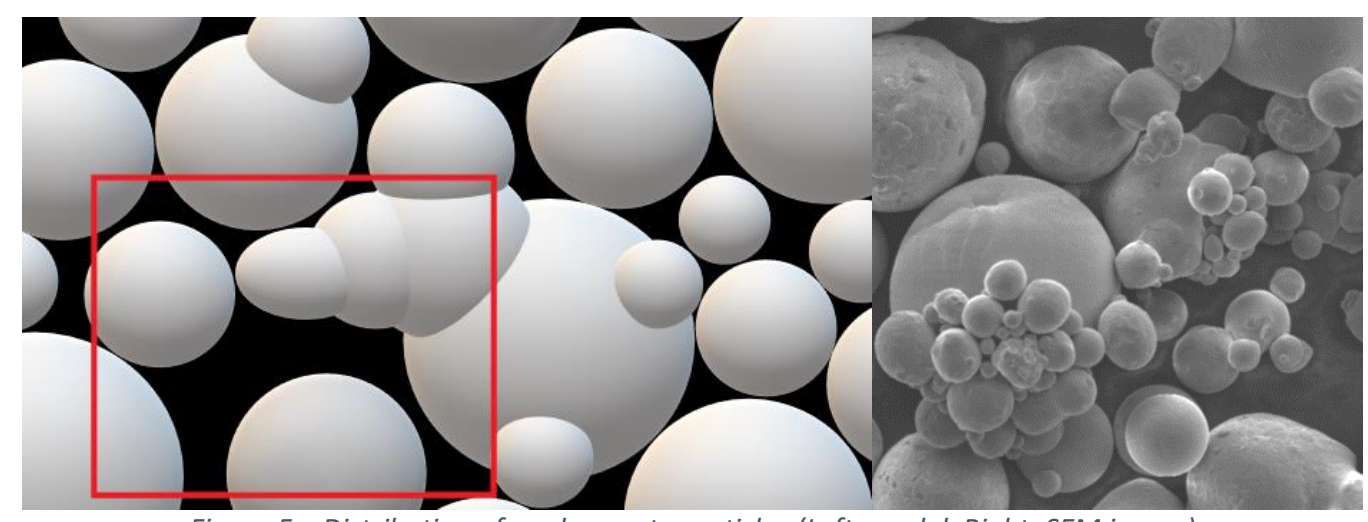

Figure 5 - Distribution of agglomerate particles (Left: model. Right: SEM image)

The rectangular outline on the model shows the region where, assuming the powder has been fed by gravity from the top of the diagram, the packing density is negatively influenced due to the agglomerates

Apparent density can be considered an indicator of particle packing in AM. To determine this, powder is allowed to flow freely to fill a vessel of a known size. Tap density is an alternative indicator of packing density, utilising mechanical action to move particles within a container to obtain an optimum packing state. As such, the tap density is typically denser than the apparent density. However, the tap density has been criticised as being an ill representation of the formation of the powder bed in AM by the spreading arm (Spierings et al., 2011). Despite this, tap density can still give an indication of changes in the powder with continual reuse. Karapatis (2002) found that the packing density of powder beds was higher than the apparent density, owing to slight compaction during the powder bed formation process, suggesting that a combination of the apparent density and tap density are needed to predict the powder bed packing.

A study recording both apparent density and tap density with powder reuse with EBM found that whilst there was no change in the apparent density, the tap density gradually decreased in Ti-6Al-4V powder (Tang et al., 2015). GranuTools (2018) found that recycled 316L stainless steel powder had both a reduced apparent density and tap density, although the number of uses is not stated. Del Re et al. (2018) found that the apparent and tap densities increased gradually with AISi10Mg powder reuse in SLM, although the virgin powder used was not as typically spherical or high-quality as is used widely in the industry. The range of contradictory information makes it difficult to ascertain what happens to powder as is it recycled, possibly due to the various parameters the powder can be subjected to during its life.

\subsubsection{Particle morphology}

The shape of individual particles plays a role in the interactions with other particles within a powder. Each particle of powder interacts with the particles surrounding it, exerting forces on one another. The cumulative result of these forces causes powder to behave differently to just one individual particle. Understanding the particle morphology is therefore essential to understanding the bulk powder properties. 
Whilst it is simple to visualise a particle as perfectly spherical, this is rarely the case. Particles will always have imperfections on their surfaces, referred to as surface roughness. The extent of this roughness influences how closely packed particles can be to one another; a rougher particle will pack less densely than a smoother one. This principle is demonstrated in Figure 6 and Figure 7. The shaded line around the particle represents the boundary around a particle where a force could be exerted on another object. As such, the region where the shaded lines overlap dictates where interparticle forces occur. As can be seen in Figure 6, smooth particles can form long regions of interparticle bonding, owing to the gentle curvature of each particle. Figure 7 shows how the rough particle edges inhibits interparticle bonding, limiting them to a smaller region. This results in weaker forces holding the particles together.
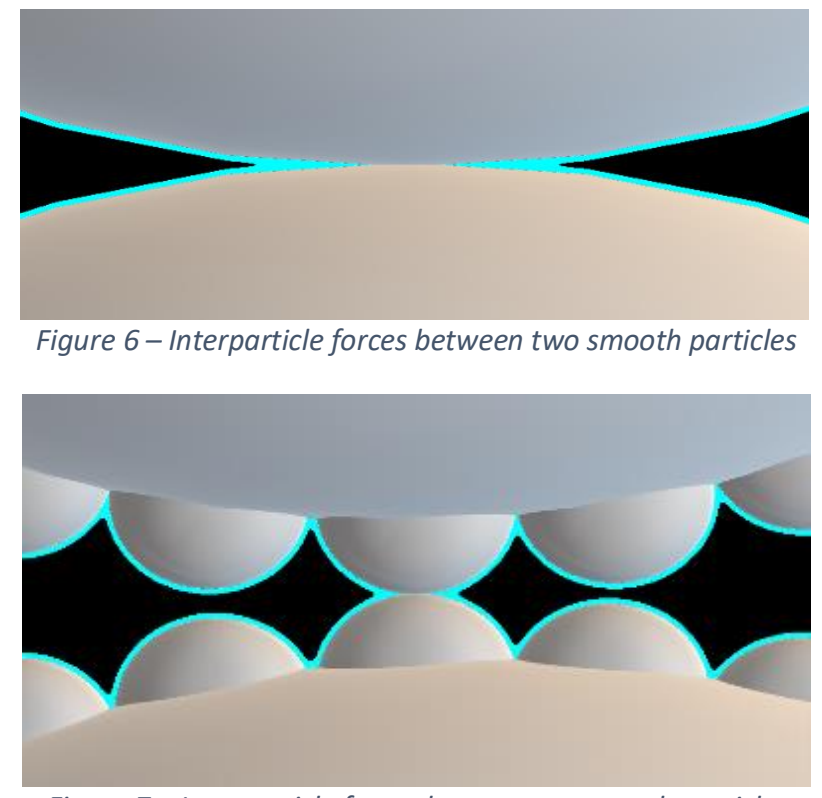

Figure 7-Interparticle forces between two rough particles

In order to understand how particles may change in morphology, knowledge of the conditions the powder is subjected to is required. The build platform is housed within a controlled environment, flooded with inert gas and kept at a constant elevated temperature. During the build process, all particles become exposed to heat from the raised chamber temperature. Many particles may be further subjected to residual heat from the laser or melt pool when in proximity to the laser's targeted location. Smaller particles have an increased surface area and so absorb energy more efficiently from the laser (Gibson et al., 2016; Simchi, 2006). This makes them more likely to melt or vaporise, whilst larger particles are less likely to fully melt.

Surface roughness occurs on a very small scale on a particle surface. A similar principle can be applied at a larger scale across an entire particle. There are two main types of morphological deformation that can occur in powder particles: satelliting and agglomeration. Partial melting, or "sintering" typically occurs at around two-thirds of the melting temperature of a metal (Slotwinski et al., 2014) and is the mechanism by which these deformations occur. Satelliting occurs when a small powder particle adjoins to a larger particle through heating. An example can be seen in Figure 8 . The large particle often does not show signs of melting or significant deformation from the spherical shape. Agglomerate particles form when two or more particles partially melt and fuse together, creating a deformed shape that can typically no longer be considered highly spherical. This is demonstrated in Figure 9. Agglomerates are likely to have more of an impact on interparticle forces 
than satellite particles due to the significantly different shape of agglomerate particles, interfering with the ability of particles to fit next to one another and pack tightly.

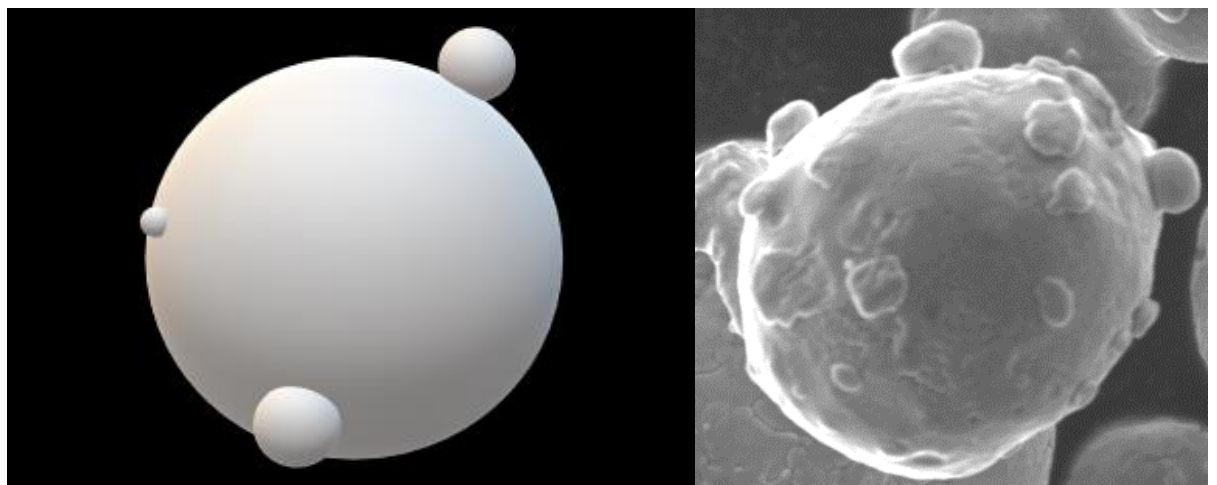

Figure 8-A particle with satellites on it (Left: model. Right: SEM image)

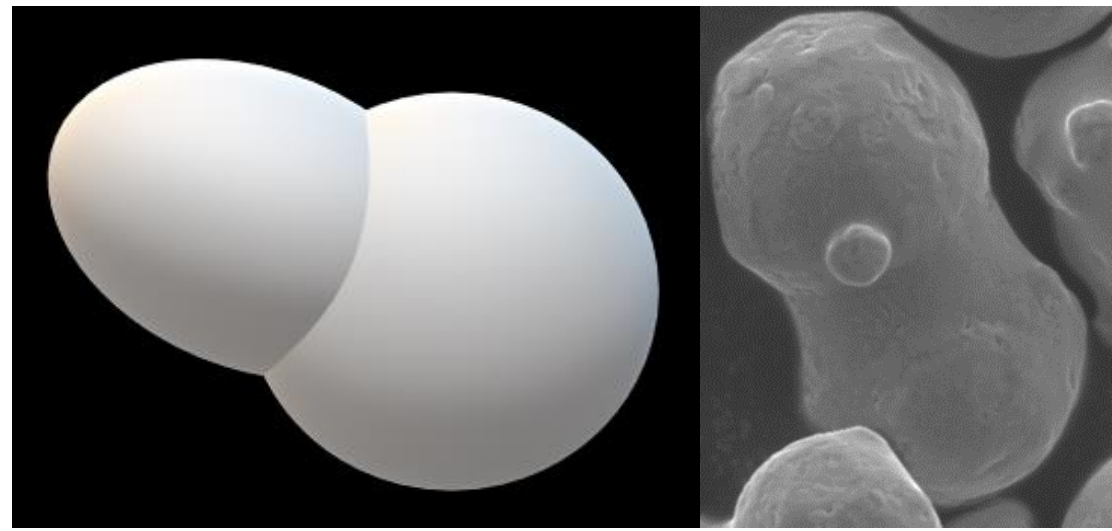

Figure 9-An agglomerate particle made of two individual particles (Left: model. Right: SEM image)

Partial melting of individual particles can also occur, causing deformation that can look similar to particle agglomeration and have similar effects on powder properties. The difference is that agglomeration requires two or more particles to fuse together, whilst partial melting does not.

These individual particle deformations are known to influence the behaviour of the powder overall. As discussed in Section 3.2.1, the PSD can be influenced by the presence of these deformed particles, causing a shift towards larger particles (Slotwinski et al., 2014; Seyda et al., 2012). This indicates that any properties affected by a change in PSD are partially influenced by powder morphology. The particles are prevented from packing closely, demonstrated and discussed in Section 3.2.2, which would influence the density of the powder bed.

Sphericity is a measure of how round a particle is. Figure 5 and Figure 6 shows that spherical particles are more desirable than deformed particles, allowing for a better packing density. It is therefore common to use the sphericity of particles as a measurement of the suitability of a powder for use within AM.

The morphology of particles has been observed to change with repeated reuse of metal powders in AM. Renishaw plc (2016) obtained SEM images of their Ti-6AI-4V powder used in SLM, observing an increase in the number of agglomerates present in recycled powder, but a reduction in the frequency of satellite particles. The majority of particles were still spherical. Another study using Ti$6 \mathrm{Al}-4 \mathrm{~V}$ showed that repeated reuse led to the increased surface roughness of the particles, although the particles remained largely spherical with very few agglomerates or satellites forming (Tang et al., 2015). Popov et al. (2018) found that there were a variety of defects present in recycled Ti-6AI-4V 
powders. Slotwinski et al. (2014) found that the sphericity of 17-4 stainless steel particles used in a PBF process began to decrease after multiple builds, although the reason for this was not stated.

Popov et al. (2018) suggest that deformation in particles occurs due to mechanical damage from the sieving process, but more importantly from exposure to heat during the AM process, causing particles to sinter. Gasper et al. (2018) observed a change in the morphology of the spatter particles (discussed in Section 3.2.4) that are inevitably produced in the AM process, suggesting that spatter particles falling back into the powder bed are likely the cause for the increase in deformed particles in recycled powders. Both of these hypotheses are supported by Renishaw plc (2016).

\subsubsection{Chemical composition}

When AM is used in industrial applications, the chemical composition of the produced component can be of great importance. Whilst some chemical variation is expected between raw materials and produced components in any manufacturing process, the chemical composition of the input material can provide an indication of whether the produced component will be suitable for the intended application.

A change in chemical composition within the powder requires chemical reactions to take place. The presence of reactive agents in the air (such as oxygen, nitrogen and carbon) allow reactions to occur, either creating a stable oxide layer around particles, dissolving deeper into the particles or forming particulates on the surface of particles (Leicht, 2018). This is minimised during metallic AM processes by pumping inert gas into the build chamber. However, this does not eliminate all contaminants; there are still traces of these reagents present during the build process. Whilst this reduces the likelihood of chemical reactions occurring, two main factors contribute to the increased reactivity of metal powders in AM: surface area and temperature.

In traditional manufacturing methods, a slab of material occupying the same volume as that of the powder would have a significantly lower surface area exposed, and may also be kept in an inert environment where necessary. In AM, metal powders expose a large surface area, increasing reactivity as there is a greater region over which reactions with contaminants can occur. Whilst this is mostly prevented by the inert gaseous environment, reactions are significantly more likely to occur during powder handling when an inert environment is not maintained.

During the build process, the build chamber is held at an elevated temperature. This reduces the dependency on the laser to melt the material and decreasing the thermal gradient between the melt pool and the surrounding powder, whilst causing minimal changes to the powder (Gibson et al., 2016). EBM requires pre-sintering and thus typically preheats the powder to high temperatures (Swift and Booker, 2013), whilst SLM does not require as much preheating (Sames et al., 2016). A rise in temperature increases the reactivity of particles, allowing chemical reactions to occur more easily.

The vast majority of reactions take place during the build process, owing to these raised temperatures. Oxides have been observed to form within the region where the laser/electron beam is focused, known as the melt pool (Gasper et al., 2018). Renishaw plc (2016) confirm this finding, further suggesting that particles close to the weld pool that are heated but not melted also pick up impurities. When the melt pool forms, particles can be seen to spark off, dispersing themselves in the build chamber. This is referred to as spatter. Gasper et al. (2018), Andani et al. (2018), Sartin et al. (2017) and Liu et al. (2015) all demonstrated the potential for spatter to form partially or entirely oxidised particles. LPW Technology Ltd (2018a) stated that whilst many oversized spatter particles are removed during sieving, a 'significant amount' of these contaminated spatter particles are small 
enough to pass through the sieve, becoming incorporated into future builds and changing the bulk powder chemical composition.

Further chemical changes can occur whilst the powder is being handled, such as during removal and sieving (Seyda et al., 2012). Although this will typically be in cool and dry conditions to minimise reactivity, the absence of an inert gas increases the number of reactive particles coming into contact with the powder. Over an extended time, this could have an impact on the chemical composition of the particles. A similar problem can occur during storage of powder, although following standard practice by storing powder in an inert gas can minimise the potential for corrosion and contamination. Little information is available on the impact of powder storage on the AM process. Besides chemical changes, dust particles, fibres and other contaminants can also mix in with powder during the handling stages (Dawes, 2019).

Reused powder sees repeated long exposures to both the residual heat and heat from the melt pool. A study by Tang et al. (2015) on Ti-6Al-4V in EBM showed a gradual and constant increase in the oxygen content coupled with a decrease in the content of aluminium and vanadium within the powder over 21 uses. Renishaw plc (2016) had remarkably similar findings for the same material in SLM over 38 reuses, seeing a gradual increase in both the oxygen and nitrogen content that led to the powder being unacceptable for Grade 23 specifications. The pickup of oxygen in Ti-6Al-4V was seen across 69 rebuilds by Popov et al. (2018) during the EBM process, exceeding the maximum ASTM F2924-14 (2014) requirement of oxygen content by $68 \%$.

The majority of spatter has been shown to fall back into the build area and may thus become incorporated into the component being built at that time (Andani et al., 2018). If this is avoided, it is likely the spatter will be cleaned out alongside the unused powder during the cleaning process. Although many spatter particles are oversized and will be removed during sieving, some spatter particles are small enough to pass through the sieve mesh (Harrison, 2019). This is one likely cause for the observed change in chemical composition as powder is recycled. LPW Technology Ltd has found that the accumulation of oxygen and nitrogen-rich spatter particles is proportional to the "laser on" time in Nickel-based powders, indicating that repeated reuse of powders will generate progressively more spatter particles and further changes to the chemical composition of a powder (Harrison, 2019).

Some sources have found a lack of change in the chemical composition as powder is recycled. Slotwinski et al. (2014) found no notable change in stainless steel powder used in SLM after the powder had been recycled eight times. Del Re et al. (2018) did not observe a notable change in AlSi10Mg powder over eight reuses in SLM, although they did not measure the presence of contaminants such as oxygen that may have been accumulating. Inconel 718 was found to have a virtually constant chemical composition after 14 reuses in the SLM process (Ardila et al., 2014).

There is a disparity as to whether or not powder changes chemically over time. This seems to be divided by materials, with Ti-6Al-4V being widely observed to pick up oxygen, whilst other materials seem to maintain a constant chemical composition. Titanium is highly reactive and is held at high temperatures to overcome the high melting point, potentially explaining why it appears to pick up contaminants more than other materials. Further to this, the number of powder reuses in literature studying non-Ti-6AI-4V materials is significantly lower than that in the Ti-6Al-4V studies considered. A change in chemical composition may not be seen until the powder is further recycled. Further research is needed into the change in chemical composition of other materials used in AM to determine the chemical degradation of these powders. 
The phase composition and microstructure of powder particles has not been considered, despite being shown to alter the melting point of a material (Liu and Shin, 2019). This decision was made as the influence of the phase composition of powder on the produced components within AM is considered to be negligible; the melt pool is sufficiently hot to completely melt the metal, causing a change in phase composition of components produced through AM.

\subsubsection{Flowability}

Flowability is a measure of how easily particles move over one another within a powder. For AM, this affects the usability of the powder, influencing how easily powder can be fed into the build chamber from a hopper. In DED, good flowability ensures a constant feed rate of powder. In PBF, flowability can influence how well the powder bed is formed beneath the coating arm. Popov et al. (2018) showed that a lack of flowability could cause a lack of fusion in the manufactured components, influencing their properties. Flowability is therefore essential in ensuring the AM process functions as designed and has the desired outputs.

The International Standards Organisation (ISO) helped produce the ISO/ASTM Standard 52907, 2019, listing four factors that can affect the flowability of the powder. These are particle size distribution, inter-particular friction (affected by surface roughness and morphology), powder moisture content and electromagnetic forces (in ferrous materials). This can be simplified by stating that flowability is determined by the forces that hold particles together. Electromagnetic forces are not further discussed, as these forces are unlikely to change during the powder recycling process.

As particle size decreases, inter-particle frictional and electrostatic forces increase due to the increased surface area over which particles can interact, reducing flowability (Gibson et al., 2016). Seyda et al. (2012) suggest that the presence of conglomerates reduces cohesive forces between particles, improving flowability. These principles can be inferred from Figure 2 and Figure 5; an increase in particle packing density allows for the formation of more interparticle forces, requiring more energy to overcome these forces to move, or "flow".

An increased moisture content leads to the additional bonds forming between particles. Water increases cohesive forces by forming liquid bridges between particles (Crouter and Briens, 2013). The bonding between water is stronger than the interparticle bonds, and thus requires more energy to overcome, resulting in a reduction in powder flowability. Moisture content can also accelerate chemical degradation of powders, demonstrated by the increased oxidation of water atomised powders (Irrinki et al., 2016) although this has not been investigated within this paper.

It has been widely observed that the flowability of the powder increases with repeated use of metal powders (Tang et al., 2015; Carroll et al., 2006; Renishaw plc, 2016). Tang et al. (2015) found that the increase was most significant after the first six powder uses than the subsequent 15 . Carroll et al. (2006) found similar results after ten powder reuses. Renishaw plc (2016) found the flowability to gradually increase with no significant initial drop off, although there were sizeable fluctuations in results. The reasons suggested for these changes vary, but PSD, powder morphology and moisture content are all mentioned. A study by GranuTools (2018) showed that virgin powder exhibited better flow rates when the aperture size through which powder flowed was larger. Otherwise, little difference was observed between virgin and recycled powder.

\subsection{Component properties}

The review of literature thus far has demonstrated the changes that arise within reused powder. It is essential to understand the impact these particle and powder properties have on components produced through AM. Little work has been done to identify correlations between individual 
variables and the build properties, most likely due to the multiple property changes occurring simultaneously with powder reuse and being difficult to isolate. This makes it difficult to determine the true cause of any changes in component properties. All references cited used the same build parameters for both their virgin powder and reused powder builds, so all differences observed are likely due to changes in the powder quality.

\subsubsection{Chemical composition}

Industries such as the aerospace and medical sectors have highly specific requirements for the components produced. Changes in chemical composition can have an influence on the mechanical properties of the component (Dong et al, 2019), causing these critical components to fail to function as designed.

The correlation between the chemical composition of the input powder and produced components was shown by Renderos et al. (2016). The difference in atomic composition of the Inconel 718 powder was found to be insignificant. Further recycling of the powder began to show an increasing change in chemical composition of the manufactured component when compared to the virgin powder. This was confirmed by Tang et al. (2015), seeing that the chemical composition of a tensile sample produced using Ti-6Al-4V powder changed gradually in line with changes in the powder chemical composition. A notable drop in aluminium content between the powder and tensile sample was observed, suggesting that for certain metals the powder chemical composition may only be indicative, but not representative, of the produced component's chemical composition. The same drop in aluminium in recycled Ti-6Al-4V was seen by Petrovic et al. (2015) as the build number increased, alongside a steady rise in the oxygen content.

\subsubsection{Density and porosity}

Pores are regions where cracks initiate under stress (Wang et al., 2012; LPW Technology Ltd, 2018b), and it is well known that increased porosity leads to a decrease in material properties in various materials (Wang et al., 2017; Cherry et al. 2015). Pores close to the surface of a specimen lead to stress concentrations which could lead to component failure (Seyda et al., 2012), whilst irregularly shaped pores with corners initiate microcracking, and thus failure, under loading (Pal et al., 2020). Reduced density is indicative of increased porosity. As such, high density components are likely to be more predictable and therefore acceptable within demanding industries.

Spierings et al. (2011) stated that fine powders tend to lead to denser parts. Irrinki et al. (2016) confirms this finding, attributing this increased part density to an improved packing density. Dawes et al. (2015) reviewed other literature, concluding that irregular shaped particles cause lower part density, whilst fine particles with a wide PSD produced high-density components. Referring to Figure 2 , the absence of differently sized and small particles prevents gaps being filled, resulting in a reduction in the packing volume of the powder bed. The shift in PSD towards larger particles observed in recycled powders may therefore contribute to a reduced part density.

Gasper et al. (2018) discuss that oxygen-rich spatter particles (highlighted in Section 3.2.4) can be integrated into the current build by falling into the build chamber, often becoming reincorporated into future builds if they are not sieved out successfully. Andani et al. (2018) believe that the porosity seen in components could be explained by the presence and creation of these spatter particles, with Liu et al. (2015) also believing that increased porosity could be due to the inclusion of oversized spatter particles that do not fully melt. Extensive research into pore formation was offered by Pal et al. (2020), demonstrating how spatter particles can be large enough to disrupt powder spreading, in turn influencing the packing density and leading to the formation of pores. Regions of incomplete melting within the component caused by oversized spatter particles, interference from 
oxidised layers on spatter particles or unsuitable build parameters were also shown to cause pore formation and internal defects. As spatter particles accumulate as powder is recycled, the inclusion of an increased number of these particles could influence the density of components produced using recycled powder.

Tang et al. (2015) found that there was a slight reduction in the density of components produced by EBM using powder recycled 16 and 21 times when compared with less heavily used powders. This was coupled with a rise in the variation of the density. However, this was still $99.55 \%$ of the maximum theoretical density of the Ti-6Al-4V. McGeehan et al. (2018) found that virgin 316L stainless steel powder yielded dense components in SLM with little variation in results, but once the powder had been reused six times the density reduced and became less predictable. Heavily used powder (number of uses unknown) was shown to produce components that were consistently less dense than virgin powder, but with a similar variance. Inconel 718 powder reused four times within a DMLD system was found to produce components with higher porosity than virgin powder, although the morphology of the pores is noted to remain consistent (Renderos et al, 2016). Ardila et al. (2014) observed a slight change in porosity between virgin and recycled Inconel 718 powder, with notably less variance in results as powder reuse increased. However, this change in porosity was not considered to be significant, even after 14 powder reuses.

Seyda et al. (2012) observed an increase in the density of SLM produced components after Ti-6AI-4V powder was recycled 12 times. Despite the reduced porosity, the size of the pores was noted to increase. This was believed to be due to a change in PSD causing more large particles to be present; any gaps in the powder bed would typically be larger than in virgin powder. Sartin et al. (2017) found that there was no consistent trend between density and powder ruse, putting any observed changes down to variations in the AM process.

\subsubsection{Tensile properties and hardness}

The tensile properties of a material include Young's modulus, Yield Strength (YS), Ultimate Tensile Strength (UTS) and the elongation. Hardness indicates how well a material can resist scratching and permanent deformation. These are essential indicators of how a material will perform when subject to certain conditions. Being able to accurately predict these properties is essential to determine the suitability of a component to its function.

Tang et al. (2015) noted an increase in oxygen content led to increased YS and UTS in Ti-6AI-4V with a constant elongation at break. Using the same alloy, Renishaw plc (2016) showed that there was a general increase in Young's modulus and UTS as the powder was continually recycled, also attributing this to the increased presence of oxygen and nitrogen in the powder, although this was not considered to be significant. Similar findings were made by Seyda et al. (2012) with Ti-6AI-4V. An initial increase in UTS was followed by a small decrease, although the UTS was still higher in this recycled powder than in virgin powder. This change was put down to an increase in pore size. Studies by LPW Technology Ltd found a correlation between the UTS and YS of Ti-6AI-4V and the oxygen concentration of the built component, which increased as the powder was recycled (Harrison, 2019). Titanium alloys are known to become brittle with increases in oxygen and nitrogen concentrations (Donachic, 2000, cited in Sames et al., 2016), so this is not representative of other materials.

Testing conducted by McGeehan et al. (2018) saw a reduction in the UTS in 316L stainless steel as the powder was reused alongside a reduction in Young's modulus. Different experimental data with $316 \mathrm{~L}$ stainless steel showed a shift towards a higher percentage of larger particles has a significant negative effect on the UTS of the produced component, owing to an increased porosity creating 
weak points (Spierings et al., 2011). This was studied and confirmed by Dong et al. (2019), alongside the finding of higher volumes of austenite (as opposed to ferrite) in low oxygen $12 \mathrm{CrNi} 2$ steel powders, explaining that austenite allows grains to slip over one another more easily, resulting in more ductile properties. Del Re et al. (2018) found that AlSi10Mg components made from recycled powder had a lower UTS and YS value when compared with virgin powder, with a general downwards trend being observed, although no significant change was observed in the elongation of tensile samples. Liu et al. (2015) found that the inclusion of spatter particles in a powder considered to be contaminated after five uses caused a reduction in the YS and UTS of produced components, although this was without sieving of the contaminated powder.

Sartin et al. (2017) found that there was no notable change in the UTS or ductility in components built from recycled powders versus virgin powder. The issue was noted that despite parameters being kept consistent, there is still a chance that other factors, such as laser muting from deposited material on the lens, could influence the quality of produced components, making it difficult to say with certainty that powder recycling rates are to blame for all observed changes.

Relatively little research has been conducted to investigate the hardness of components made from recycled powders. Seyda et al. (2012) found a slightly increased hardness in components built from recycled Ti-6AI-4V powder, explaining that this change was likely due to the increased oxygen content of the Ti-6AI-4V powder. Carroll et al. (2006) found that there was a reduction in hardness after just one powder reuse cycle with Inconel 718 , with all subsequent builds remaining at this reduced hardness value.

There are notable differences with powder reuse between common AM alloys. Seemingly Ti-6Al-4V has increased material properties as the powder gets recycled, but the opposite is seen in other materials. Any deviation from the component properties produced when using recycled powder as opposed to virgin powder can cause difficulties when predicting component properties, demonstrating the potentially negative effect of powder recycling material properties.

\subsubsection{Surface roughness}

Surface roughness is an indication of the build resolution and can thus indicate how accurately a part is being made. Further to this, polished components with a smoother surface can fail in various locations, with crack initiation happening anywhere in the metal, whereas as-printed builds crack along the rough edges between layers of the deposited material (Sames et al., 2016). Polishing of components has been shown to improve fatigue resistance, most likely due to the absence of these rough edges allowing cracks to easily form and propagate (Wycisk et al., 2014).

The roughness between layers can be visualised in Figure 10, where the edge of each layer is slightly rounded off. A rougher surface will require more post-processing to smooth the cracks between layers, as additional protruding material needs to be removed, seen in Figure 11. Additional postprocessing to polish materials and increase their material properties can be both costly and time consuming, and is therefore undesirable. 


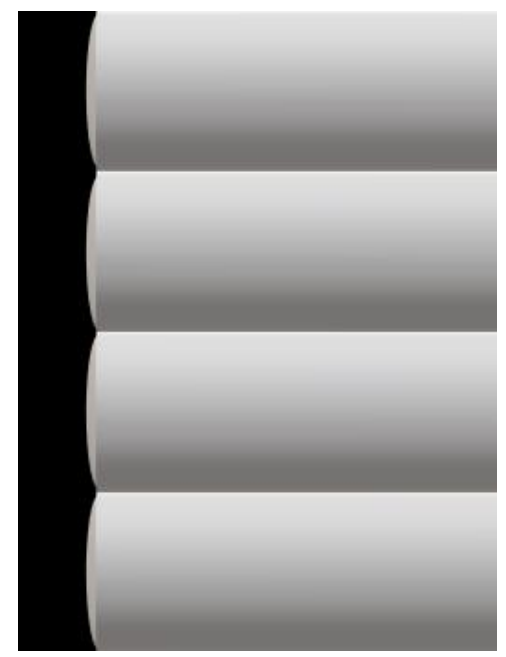

Figure 10 - An example of low surface roughness between layers

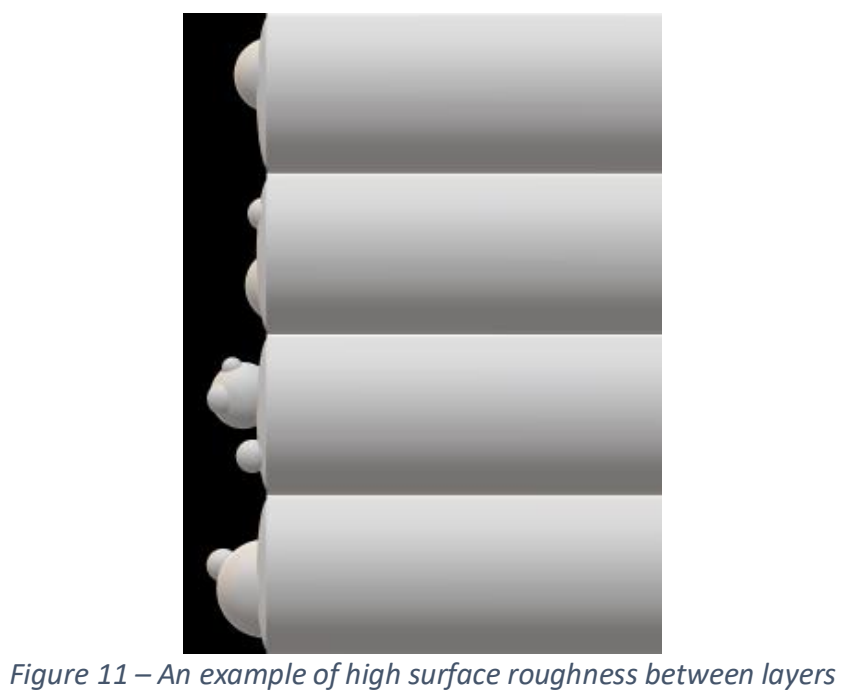

Surface roughness was negatively affected with repeated reuse of Ti-6Al-4V powder, showing a constant increase over 12 powder reuses, increasing in line with the increased presence of large particles in the PSD (Seyda et al., 2012). It was suggested that the large particles begin to melt and attach to the surface of the exposed component, making it rougher. An increase in surface roughness in Inconel 718 components created through DED was also observed by Carroll et al. (2006), which saw an increase from $8.5 \mu \mathrm{m}$ to $19 \mu \mathrm{m}$ after ten reuses of the powder. A study conducted on 316L stainless steel SLM components showed that the surface roughness of components produced from virgin powder increased compared to powder recycled six times, although a large variation was seen in the results (McGeehan et al., 2018). Spierings et al. (2011) showed that a powder with a PSD with more large particles produced rougher components than finer powders. It was further stated that the surface roughness can be improved by reducing the scan speed, giving larger particles more time to fully melt.

\subsection{Combining virgin and recycled powder}

It is common practice to extend the lifespan of used powder by mixing it with virgin powder. This can reduce the effect of the powder degradation seen in reused powders. All literature reviewed thus far focuses on the repeated recycling of powder, without the addition of new virgin powder.

Comparatively little research has been carried out on the effect of combining powders of differing quality, despite being widely utilised within industry. 
Research by Vock et al. (2018, cited in Vock et al., 2019) saw that powder mixed equal parts virgin and recycled after each cycle in a PBF process saw no change in the PSD or flowability. Extrapolation of this indicates that other powder properties may not change either in this powder mixture. No work was done to test the impact of this powder recycling method on the component properties. However, as particle and powder properties have thus far been shown to affect the quality of components produced by AM, this could indicate that components produced through this powder reusage technique maintain consistent with predictable properties.

Jacob et al. (2017) used a powder recycling technique in SLM with 17-4 stainless steel that introduced virgin powder to the build after five cycles and mixed the powder homogenously. Apart from this, powder was predominantly recycled from the previous build, but also utilised some powder from older builds. This led to creation of components utilising a non-homogenous blend of powders with various recycle rates.

Through this recycling process, powder properties had various changes. The morphology of particles remained constant, whilst the PSD appeared to shift towards smaller particles. This shift was explained as the PSD sample was taken using powder from the powder bed, which is known to sweep larger particles to the overflow bin, allowing more small particles from the virgin powder to be integrated into the powder bed.

The flow rate was seen to increase, as in other recycled powders. The apparent density steadily increased as the powder was repeatedly recycled, except when virgin powder was reintroduced after the fifth cycle, reducing the apparent density. Jacob et al. also recorded that the powder bed density increased in recycled powder combined with new virgin powder. The chemical composition was observed to stay constant.

Components produced during this study were observed to have relatively constant properties. The surface roughness showed a large variation between results, but the introduction of virgin powder after the fifth cycle caused a notable increase in roughness, contrary to expectation. The density of the component increased with a higher percentage of virgin powder present, but remained relatively constant throughout. Hardness values remained consistent, as did the UTS. The YS decreased as the quantity of virgin powder present decreased, indicating that virgin powder is preferable, but demonstrates the positive effect that mixing recycled powder with virgin powder can have.

More research needs to be done to investigate the effect of mixing virgin and recycled powders. Promising results have been seen, indicating that the impact of powder reuse is minimised through this technique. However, until these are tested on a range of materials under different conditions, AM users will be unable to achieve the maximum longevity and potential from their powders.

\subsection{End-of-life (EoL) powder}

The difficulty of disposing of powders has been identified as an issue in AM (Ian Brooks 2019, personal communication). Minimising the waste produced reduces the need for companies to invest into safe disposal of their powders, saving them money whilst also reducing their environmental impact.

A combination of virgin and recycled powder has been demonstrated to improve powder longevity. Even through this practice, $12.5 \%$ of virgin powder ends up as waste, with potentially more produced in high-end industries (Louise Geekie 2018, personal communication). Sartin et al. (2017) found that $6.7 \%$ of the powder introduced to the build chamber in SLM was consumed. $2-3 \%$ was used to create components. Approximately $1 \%$ of powder per build was collected in the filtration system, and the remainder was consumed during the clean-out process. The remaining $93.3 \%$ of the 
powder was recovered and recycled repeatedly until it could no longer be reused, eventually creating the $12.5 \%$ of waste powder.

In order for combined virgin and used powder to be used effectively, careful logging of the usage history and build conditions of each powder is required, alongside the percentage of each powder used in the combination. However, this can only provide an indication of how the powder will behave. Technologies such as LPW Technology Ltd's PowderSolve provide this capability, allowing the component properties to be predicted, although this is in the early days of development and adoption. This can help to determine when powder could no longer be suitable for use in AM, thus needing a top up of virgin powder or removal from the AM cycle.

Besides mixing recycled powder, alternate avenues for EoL powder are not identified. If companies have identified solutions to give them a competitive edge in the AM market, this information would not likely be available in the public domain. Fine particles vaporise rather than melt (Carroll et al., 2006; Gasper et al., 2018), making the scrapping of powders difficult and unprofitable for recycling plants. Even if processes were identified to repurpose waste powder, the value of scrap metal is typically only $1-3 \%$ of the initial cost of virgin powder, making them unlikely to be profitable. As a result of this, companies in the AM industry do not have a means of upcycling their EoL powder, often sending their waste powder to landfill or paying to have it removed safely (lan Brooks 2019, personal communication).

The need for the safe removal of powders comes from the potential for metal powders to become combustible and ignite, causing an explosion and potentially severe damage. Investigation by Jacobson et al. (1964) shows that particles of stainless steel are in the "none" category of Relative Explosion Hazard Index, even with $100 \%$ of the powder smaller than $44 \mu \mathrm{m}$. However, the report showed a serious risk with other metal powders, notably in titanium and aluminium alloys. These energetic powders often require safe, and sometimes costly, removal from site, hampering the profitability of the process.

The various rates of degradation in powders have been seen in Section 3.2, owing to different powder feedstocks, process parameters, builds and powder handling techniques. There are numerous factors affecting the quality of the produced component. As such, identifying the EoL point of powders is somewhat arbitrary. Standards in place, such as ASTM F3055 (2014) for AM using Inconel 718 in PBF, do not offer official guidelines on powder reuse or identification of EoL powders. This causes a large variation in what AM users consider "unusable" powder.

EoL powder has been an issue since the inception of metallic powder-based AM, and yet seemingly little research has been done to identify solutions to this. Research needs to be aimed at identifying methods to extend the lifespan of metal powders and prevent unusable powder from going to landfill.

\section{Discussion - Identified solutions}

Any solution is environmentally preferable to sending powder to landfill. However, a solution needs to be economically viable for it to become adopted by the industry, as it may be cheaper to purchase new virgin powder than attempt to upcycle the EoL powder. This poses a significant challenge and may be the reason for the lack of research in this field. Within this section, solutions have been identified to extend the longevity of powder to prevent disposal, carrying out preliminary investigations into their potential for adoption within the AM community. 
There are likely many other potential solutions that could reduce waste within the AM community. Powell (2020) identified and analysed several additional solutions beyond those listed below. These are not included for brevity.

\subsection{Powder regrading}

When powder is delivered from the supplier to the AM user, the AM user could send any EoL powder back to the original supplier at no cost. The powder supplier will have access to testing facilities that will allow them to determine the quality of this EoL powder. This powder could then be mixed with virgin powder or other powders to create a powder blend to a new specification, assisted by research into the optimum mixing fractions. The cost of this additional work could be offset by the profits made by the company in reselling the regraded powder that they have received at no cost. This would reduce the quantity of powder being sent to landfill, whilst also reducing the quantity of virgin powder that needs to be produced.

Encouraging powder suppliers to consider this as an option is the only means of determining if this solution would be acceptable. Not all AM users require the highest-grade powders, especially in noncritical components. As such, there may be a market for this lower-grade powder. To further encourage powder suppliers to consider this, the impact of mixing EoL powder with virgin powder should be investigated. If it can be demonstrated that there is a negligible change in powder that contains as little as $2 \%$ EoL particles, if not more, powder suppliers would be more receptive to this idea.

\subsection{Plasma spheroidising}

General Electric Co (GE) are developing a technique called plasma spheroidisation, capable of improving the properties of powders that are used as feedstock (Kelkar, 2018). The basic principle is shown in Figure 12. By melting the outmost layers of the particle, the size of particles decreases to within acceptable parameters for use in SLM, whilst the particles become more spherical. The oxygen, nitrogen and hydrogen content reduced between the powder feedstock and the powder output significantly, forming powders similar to gas atomised powder from a water atomised feedstock. These claims are supported by Boulos (2012), claiming that spheroidisation could improve flowability, packing density, particle porosity, surface morphology and powder purity.

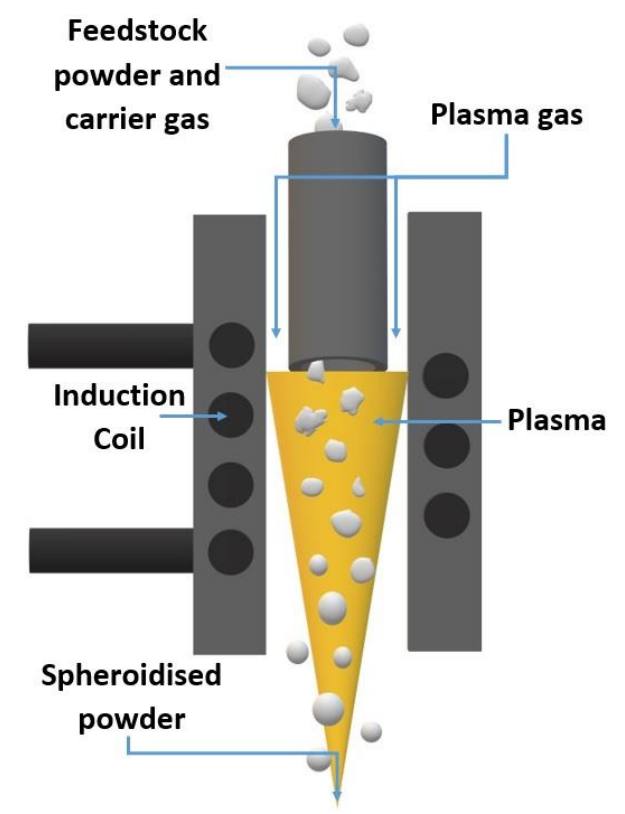

Figure 12 - An overview of plasma spheroidisation 
Further to this, GE state that alloying elements can be mixed into the feedstock powder to change the chemical composition of the output powder, allowing a powder to be chemically altered to fall within a specification. This was demonstrated by O'Dell et al. (2004), showing that a composite powder of pure molybdenum and rhenium could produce a powder alloy of these constituent elements when fed into a plasma spheroidiser. In this same experiment, the oxygen content was also seen to decrease by $97 \%$. This significant result demonstrates that feedstock powder could be chemically altered to match or surpass the quality of virgin powder produced through the widely accepted gas atomisation process.

Plasma spheroidisation has also been investigated by other major powder suppliers. LPW Technology Ltd (2016) found that particles produced using a spheroidiser were highly spherical, although the reduction in size seen in the study by GE was not reproduced. Particle sizes remained constant in two materials and increased in size in a third. It was believed that tweaking the parameters used in plasma spheroidisation caused these changes. This was confirmed by Kobiela et al. (2015), finding that both the quality of the feedstock material and process conditions heavily influenced the output of the spheroidised material. Despite allegedly optimising the process, small cracks and pores were seen on the surface of spheroidised tungsten powder.

Studies of the spheroidisation process tend to use heavily misshapen non-spherical powders as their feedstock, produced from water atomisation, chemical reactions or mechanical processes. These powders are typically in a worse state than the EoL powders that are being considered as a feedstock for the plasma spheroidisation process. Therefore, it is highly probable that using EoL powder as a feedstock material will produce particles of a similar or higher quality than those used in the reviewed literature.

Sartin et al. (2017) reported that of the $93.3 \%$ of powder recovered for recycling per build, a further $3 \%$ of this powder was removed during the sieving process. Sieved out particles therefore represent a portion of the waste in $\mathrm{AM}$, on top of the $12.5 \%$ of waste powder produced. Approximately one kilogram of unusable powder is created per kilogram of components produced through AM (Sartin et al., 2017). If a sufficient quantity of these particles could be collected, it is likely that they could also be used as a feedstock powder for the spheroidisation process, further reducing the waste produced by the AM industry.

The potential energy savings of this technology can be demonstrated through data provided by Tekna (n.d.) on their TekSphero-200 spheroidisation system. A throughput of 5-50kg of powder can be achieved per hour, utilising up to $200 \mathrm{~kW}$ of power. Boulos (2012) showed that a lower powder throughput rate dramatically increased the tap density of the produced powder, representative of increased sphericity of particles. However, as the feedstock powder is already highly spherical, it can be assumed the maximum throughput can be utilised. If this were combined with the highest machine power setting, one kilogram of powder would require $4 \mathrm{kWh}$ to produce. This equates to $14.4 \mathrm{MJ}$ of energy per kilogram of powder produced, utilising only $81.7 \%$ of the energy required in the direct atomisation process of steel powders. It is highly probable that steel would not require this much energy to spheroidise; Boulos (2012) used only 100kW to spheroidise molybdenum, which has a melting point $1200^{\circ} \mathrm{K}$ higher than steel. Therefore, this value may be further reduced. This powder upcycling method is therefore likely to be preferable to produce high-quality powders for AM than atomisation, both reducing EoL powder waste and reducing energy consumption in the creation of new powders.

Subjecting EoL powder to a plasma spheroidiser and examining the output powder is the next logical step to ensure the suitability of this process for repurposing metal powders. Utilising these improved 
powders in the AM process to create components is another essential step to prove the usability of these powders, but has not yet been investigated. These tests should be conducted on a variety of materials to determine their behaviour. Ti- $6 \mathrm{Al}-4 \mathrm{~V}$ accounts for $63 \%$ of revenue in the metal AM industry (Grand View Research, 2019) and often has the highest quality requirements, so should be prioritised. Upscaling the design of the spheroidiser to maximise the throughput of powder would also be essential, improving the financial viability of this solution.

\subsection{High-quality powder feedstock}

It is probable that a higher quality virgin powder is more likely to have an extended lifespan, so could be worth the extra up-front cost to companies. This is confirmed in a basic case study by LPW Technology Ltd; by investigating the rate of oxygen pick up in recycled Ti-6Al-4V, powder that was hypothesized to be $16.7 \%$ more expensive was estimated, over the useful lifespan, to reduce the cost of parts by $60 \%$ (Rushton, 2019). This is further demonstrated by Renishaw plc (2016), where a Ti-6Al-4V powder that had a lower concentration of oxygen to start with was estimated to be usable in more builds, before the maximum acceptable oxygen content in produced components was reached. However, this case study only considers the chemical composition of the components produced; other particle or powder properties could cause a powder to be unsuitable for use in AM before the maximum oxygen content is reached. However, as powder degradation has been largely shown to be gradual across a multitude of properties, this solution is promising.

This practice could reduce the quantity of virgin powder that is manufactured using the energyintensive atomisation process, leading to a reduction in energy consumption in the overall AM industry. Research comparing several powders of various qualities should be carried out to further investigate if higher quality powders significantly extend the lifespan of the powder. However, this does not prevent EoL powders from being disposed of; the disposal process is merely postponed.

\subsection{Identifying end-of-life powder}

There may be little need to monitor powder characteristics as powder is recycled. Whilst powder properties may be indicative of how well an AM component will fabricate, the literature review shows that there are many complex factors to consider that change in tandem. The components produced from the powder are evidently more indicative of how well the powder will perform.

Building standardised testing samples (such as tensile and hardness samples) at regular points throughout the recycling process would allow for determination of the AM build quality. The results from testing of the samples could be compared to previous known results. When the samples no longer meet acceptable values, the powder should no longer be considered for use in AM, enabling maximum powder usage until this point.

The downside to this solution is cost. Some AM users may not have access to material testing facilities, needing to either outsource testing or investment in costly equipment. If a significant correlation could be identified between one single powder property that could be easily tested and the quality of a produced AM component, testing of this powder property could identify EoL powders. This would provide a significantly cheaper solution for companies with the additional benefit of reducing waste through testing samples and power consumption.

This has been investigated by Vock et al. (2019), stating that powder qualification could not be achieved through current standardised methods and that more complex powder characterisation methods may be needed. However, GranuTools (2016) have produced a device called the GranuDrum capable of measuring multiple rheological properties of powder inside a small rotating cylinder. The current standards laid out by ISO/ASTM 52907 identify four potential methods of 
determining the flowability, but note that a rotating cylinder is a better measurement to understand powder when it is both flowing freely and non-freely. As this technology has not been widely investigated, further research into powder properties determined by a GranuDrum and the produced component properties from this powder could show a previously unidentified correlation. This could in turn be used to identify the EoL point of metal powders.

This solution would reduce the time and resources spent analysing powder characteristics after each build. Once again, whilst this may improve the longevity of powder and reduce the cost of determining the EoL points of powders, it does not prevent powders from being sent to landfill.

\section{Conclusions}

The literature shows that powder degrades with repeated recycling in several ways. Powder degradation can be seen to have an impact on the properties of components produced through AM, typically in an undesirable manner. As the rate of degradation is typically slow, powders can be successfully reused multiple times before they are no longer fit for purpose.

With many properties changing after each powder use, it is hard to identify which change is affecting the component properties. Different materials do not age in the same way, and the same material will age differently when subject to different parameters. This makes it difficult to accurately predict powder degradation, and thus troublesome to determine the point at which metal powders are no longer acceptable for use within AM. Suggestions have been made to both delay and establish when these powders should no longer be reused, with research avenues proposed to determine the viability of these suggestions.

The disposal of metal powders was identified as a significant source of waste in this otherwise highly efficient technology. Whilst several solutions have been identified to prevent or slow the disposal of these powders, one is believed to be appealing to the entire industry. The adoption of powder spheroidisers within the AM industry could revolutionise the AM process, making this already clean technology produce almost zero waste. Further investigation into this technology is needed to demonstrate its effectiveness. This may encourage the rapid adoption of plasma spheroidisers, in turn reducing the waste produced by the AM industry. With the increasing uptake of AM, reduction of waste now will have a significant impact on the cleanliness of this technology in the future.

\section{Acknowledgements}

The authors would like to thank the European Regional Development Fund part-funded EcoInnovation Cheshire and Warrington project [Grant Reference 03R17PO1835] for the financial support contributing to the research presented in this paper. Further gratitude is extended to the Centre for Global Eco-Innovation at Lancaster University.

\section{References}

Additive Manufacturing UK (2017) “National Strategy 2018-25” [online] Available here: http://amuk.org/wp-content/uploads/2017/11/AM-UK Strategy Publication Amends Novermber Digital.pdf (Accessed: August 23, 2019)

Andani, M.T., Dehghani, R., Karamooz-Ravari, M.R., Mirzaeifar, R. and Ni, J. (2018) "A study on the effect of energy input on spatter particles creation during selective laser melting process" Additive Manufacturing, 20, pp. 33-43. https://doi.org/10.1016/i.addma.2017.12.009

Ardila, L., Garciandia, F., González-Díaz, J., Álvarez, P., Echeverria, A., Petite, M., Deffley, R. and Ochoa, J. (2014) "Effect of IN718 Recycled Powder Reuse on Properties of Parts Manufactured by 
Means of Selective Laser Melting" Physics Procedia, 56, pp. 99-107.

https://doi.org/10.1016/j.phpro.2014.08.152

ASTM F2924-14 (2014) "Standard Specification for Additive Manufacturing Titanium-6 Aluminum-4 Vanadium with Powder Bed Fusion" ASTM International, West Conshohocken, PA

ASTM F3055-14a (2014) "Standard Specification for Additive Manufacturing Nickel Alloy (UNS N07718) with Powder Bed Fusion" ASTM International, West Conshohocken, PA

Boulos, M. (2012) "New frontiers in thermal plasmas from space to nanomaterials" Nuclear Engineering and Technology, 44(1) https://doi.org/10.5516/NET.77.2012.001

Bourhis, F.L., Kerbrat, O., Dembinski, L., Hascoet, J.Y. and Mognol, P. (2014) “Predictive Model for Environmental Assessment in Additive Manufacturing Process" Procedia CIRP, 15, pp. 26-31. https://doi.org/10.1016/i.procir.2014.06.031

Campbell, T., Williams, C., Ivanova and O., Garrett, B. (2011) “Could 3D Printing Change the World?" Washington DC: Atlantic Council.

Carroll, P.A., Brown, P., Ng, G., Scudamore, R., Pinkerton, A.J., Syed, W., Sezer, H., Li, L. and Allen, J. (2006) "The Effect of Powder Recycling in Direct Metal Laser Deposition on Powder and Manufactured Part Characteristics" RTO-MP-AVT-139.

Cherdo, L. (2019) “The best Metal 3D printers in 2019" [online], Available at:

https://www.aniwaa.com/best-of/3d-printers/best-metal-3d-printer/ (Accessed: August 23, 2019)

Cherry, J. A., Davies, H. M., Mehmood, S.N., Lavery, P., Brown, S. G. R., and Sienz, J. (2015)

"Investigation into the effect of process parameters on microstructural and physical properties of 316L stainless steel parts by selective laser melting" International Journal of Advanced

Manufacturing Technology, 76, pp. 869-879. https://doi.org/10.1007/s00170-014-6297-2

Crouter, A. and Briens, L. (2013) "The Effect of Moisture on the Flowability of Pharmaceutical Excipients" AAPS PharmSciTech, 15(1), pp. 65-74 https://doi.org/10.1208/s12249-013-0036-0

Dawes, J. (2019) "Powder Management in Additive Manufacturing" Mastering AM: Sharing User Experience, 27th March, Coventry, United Kingdom

Dawes, J., Bowerman, R. and Trepleton, R. (2015) "Introduction to the Additive Manufacturing Powder Metallurgy Supply Chain" Johnson Matthey Technology Review, 2015, 59, (3), pp. 243-256. https://doi.org/10.1595/205651315×688686

Del Re, F., Contaldi, V., Astarita, A., Palumbo, B., Squillace, A., Corrado, P. and Di Petta, P. (2018) "Statistical approach for assessing the effect of powder reuse on the final quality of AISi10Mg parts produced by laser powder bed fusion additive manufacturing" International Journal of Advanced Manufacturing Technology, 97(5-8), pp. 2231-2240 https://doi.org/10.1007/s00170-018-2090-y

Dong, Z., Kang, H., Xie, Y., Chi, C. and Peng, X. (2019) "Effect of powder oxygen content on microstructure and mechanical properties of a laser additively-manufactured $12 \mathrm{CrNi2}$ alloy steel" Materials Letters, 236, pp. 214-217. https://doi.org/10.1016/j.matlet.2018.10.091

Faludi, J., Baumers, M., Maskery, I. and Hague, R. (2016) "Environmental Impacts of Selective Laser Melting: Do Printer, Powder, Or Power Dominate?" Journal of Industrial Ecology, 21(S1). https://doi.org/10.1111/jiec.12528

Gasper, A., Szost, B., Wang, X., Johns, D., Sharma, S., Clare, A. and Ashcroft, I. (2018) "Spatter and oxide formation in laser powder bed fusion of Inconel 718" Additive Manufacturing, 24, pp. 446456. https://doi.org/10.1016/j.addma.2018.09.032

Gibson, I., Rosen, D.W. and Stucker, B. (2016) “Additive manufacturing technologies: 3D printing, rapid prototyping, and direct digital manufacturing" New York: Springer. 
Grand View Research (2019) "3D Printing Metal Market Size, Share \& Trends Analysis Report By Form (Filament, Powder), By Product (Steel, Titanium, Nickel), By Application (Medical, Aerospace \& Defense), And Segment Forecasts, 2019 - 2025" [online] Available at:

https://www.grandviewresearch.com/industry-analysis/3d-metal-printing-market (Accessed: August 23, 2019)

GranuTools (2016) "GranuDrum", Available at: https://granutools.com/products/granudrum/ (Accessed: August 23, 2019)

GranuTools (2018) "Investigation of Powders ageing for Additive Manufacturing Process" [online], Available at: https://granutools.com/references/application-notes/highlighting-reproducibilitypowders-ageing/ (Accessed: August 23, 2019)

Harrison, N. (2019) "Powder specification workshop" Mastering AM: Sharing User Experience, 27th March, Coventry, United Kingdom

Herzog, D., Seyda, V., Wycisk, E. and Emmelmann, C. (2016), "Additive manufacturing of metals" Acta Materialia, 117, pp. 371-392. https://doi.org/10.1016/i.actamat.2016.07.019

Irrinki, H., Dexter, M., Barmore, B., Enneti, R., Pasebani, S., Badwe, S., Stitzel, J., Malhotra, R. and Atre, S.V. (2016) "Effects of Powder Attributes and Laser Powder Bed Fusion (L-PBF) Process Conditions on the Densification and Mechanical Properties of 17-4 PH Stainless Steel" Journal of the Minerals, Metals \& Materials Society, 68(3), pp. 860-868. https://doi.org/10.1007/s11837-015$\underline{1770-4}$

ISO/ASTM 52907 (2019) " Additive manufacturing - Feedstock materials - Methods to characterize metal powders" ASTM International, West Conshohocken, PA

Jacob, G., Brown, C., Donmez, M., Watson, S. and Slotwinski, J. (2017) "Effects of powder recycling on stainless steel powder and built material properties in metal powder bed fusion processes" National Institute of Standards and Technology. https://doi.org/10.6028/NIST.AMS.100-6

Jacobson, M., Cooper, A.R. and Nagy, J. (1964) "Explosibility of metal powders" [online], Available here: https://apps.dtic.mil/dtic/tr/fulltext/u2/b270510.pdf (Accessed: August 23, 2019)

Javidrad, H. Erfan, A., Larky, M. and Riahi, M. (2018) "Investigation in environmental and safety aspects of additive manufacturing (AM)" 5th International Reliability and Safety Engineering Conference, $9^{\text {th }}-11^{\text {th }}$ May, Shiraz, Iran

Karapatis P. (2002) "A sub-process approach of selective laser sintering" Doctoral thesis, EPFL, Lausanne, Switzerland https://doi.org/10.5075/epfl-thesis-2506

Kelkar, R. M. (2018) “High Quality Spherical Powders for Additive Manufacturing Processes Along With Methods of Their Formation" US20190061005A1

Kobiela, K., Smolina, I., Frankiewicz, M. and Chlebus, E (2015) “Plasma spheroidisation of high melt point materials on example of tungsten" Welding Technology Review, 87, pp. 31-34.

https://doi.org/10.26628/ps.v87i11.526

Leicht, A. (2018) "Aspects of building geometry and powder characteristics in powder bed fusion" Licentiate Thesis, Chalmers University of Technology, Gothenburg, Sweden

Li, R., Shi, Y., Wang, Z., Wang, L., Liu, J. and Jiang, W. (2010) "Densification behavior of gas and water atomized 316L stainless steel powder during selective laser melting," Applied Surface Science, 256(13), pp. 4350-4356. https://doi.org/10.1016/i.apsusc.2010.02.030

Liu, S. and Shin, Y.C. (2018) "Additive manufacturing of Ti6Al4V alloy: a review" Materials \& Design, 164, https://doi.org/10.1016/i.matdes.2018.107552 
Liu, Y., Yang, Y., Mai, S., Wang, D. and Song, C. (2015) “Investigation into spatter behavior during selective laser melting of AISI 316L stainless steel powder" Materials \& Design, 87, pp. 797-806. https://doi.org/10.1016/i.matdes.2015.08.086

LPW Technology Ltd (2016) "Case Study 07: Plasma Spheroidisation" [online] Available here: https://carpenteradditive.com/wp-content/uploads/2016/09/LPW-Case-Study-07.pdf (Accessed: August 23, 2019)

LPW Technology Ltd (2018a) "Metal powder reuse regimes and impact on part reproducibility - Part I" [online] Available here: http://maschinetech.com/wp-content/uploads/2018/06/PowderDegradation-in-Serial-Production-Pt-I.pdf (Accessed: August 23, 2019)

LPW Technology Ltd (2018b) "The impact of powder variability on Additive Manufacturing build quality" [online] Available here: https://www.carpenteradditive.com/news/impact-of-metalpowder-variability-on-build-quality/ (Accessed: 10th September 2019)

McGeehan, O., Oldfield, S., Wilks, J., Mawby, J. and Linaker, L. (2018) "Testing and Analysis of Additive Manufactured Parts from Partially Recycled Powder" MEng thesis, Liverpool John Moores University, Liverpool.

Morrow, W.R., Qi, H., Kim, I., Mazumder, J. and Skerlos, S.J. (2007) “Environmental aspects of laserbased and conventional tool and die manufacturing", Journal of Cleaner Production, 15 (10), pp. $932-$ 943. https://doi.org/10.1016/j.jclepro.2005.11.030

O'Dell, J.S., Schofield, E.C., McKechnie, T.N. and Fulmer, A. (2004) "Plasma Alloying and Spheroidization Process and Development" Journal of Materials Engineering and Performance, 13(4), pp. 461-467. https://doi.org/10.1361/10599490419946

Pal, S., Lojen, G., Gubeljak, N., Kokol, V. and Drstvensek, I. (2020) “Melting, fusion and solidification behaviors of Ti-6AI-4V alloy in Selective Laser Melting at different scanning speeds", Rapid Prototyping Journal, Accepted (in Press)

Petrovic, V., Gonzalez, J.V.H., Ferrando, O.J., Gordillo, J.D., Puchades, J.R.B. and Griñan, L.P. (2010) "Additive layered manufacturing: sectors of industrial application shown through case studies" International Journal of Production Research, 49(4), pp. 1061-1079.

https://doi.org/10.1080/00207540903479786

Piller, F.T., Poprawe, R., Schleifenbaum, H.J., Schuh, G., Barg, S., Dolle, C., Hinke, C., Jank, M.-H., Jiang, R., Meiners, W., Riesener, M., Schrage, J. and Ziegler, S. (2018) "Introducing a Holistic Profitability Model for Additive Manufacturing: An Analysis of Laser-powder Bed Fusion," 2018 IEEE International Conference on Industrial Engineering and Engineering Management (IEEM), pp.17301735. https://doi.org/10.1109/IEEM.2018.8607729

Popov, V. V., Katz-Demyanetz, A., Garkun, A. and Bamberger, M. (2018) "The effect of powder recycling on the mechanical properties and microstructure of electron beam melted Ti-6Al-4V specimens" Additive Manufacturing, 22, pp. 834-843 https://doi.org/10.1016/i.addma.2018.06.003

Powell, D. (2020) "Recycling and reuse of metal powders for various applications in additively manufactured products" MSc thesis, Lancaster University, Lancaster

Rasband, W.S.(1997-2018) “ImageJ" U. S. National Institutes of Health, Bethesda, Maryland, USA, https://imagej.nih.gov/ij/

Renderos, M., Girot, F., Lamikiz, A., Torregaray, A. and Saintier, N. (2016) "Ni Based Powder Reconditioning and Reuse for LMD Process" Physics Procedia, 83, pp. 769-777.

https://doi.org/10.1016/j.phpro.2016.08.079

Renishaw plc (2016) "Investigating the effects of multiple re-use of Ti6AI4V powder in additive manufacturing (AM)" [online] Available here: https://resources.renishaw.com/en/details/white- 
paper-investigating-the-effects-of-multiple-powder-re-use-in-am--83164 (Accessed: August 23, 2019)

Rushton, J. (2019), "Powder management in Additive Manufacturing" Mastering AM: Sharing User Experience, 27th March, Coventry, United Kingdom

Sames, W. J., List, F. A., Pannala, S., Dehoff, R. R. and Babu, S. S. (2016) "The metallurgy and processing science of metal additive manufacturing" International Materials Reviews, 61(5), pp. 315360. https://doi.org/10.1080/09506608.2015.1116649

Sartin, B., Pond, T., Griffith, B., Everhart, W., Elder, L., Wenski, E., Cook, C., Wieliczka, D., King, W., Rubenchik, A., Wu, S., Brown, B., Johnson, C. and Crow, J. (2017) "316l Powder Reuse For Metal Additive Manufacturing" 28th Annual International Solid Freeform Fabrication Symposium - An Additive Manufacturing Conference, $7^{\text {th }}-8^{\text {th }}$ August, Austin, Texas

Seyda, V., Kaufmann, N. and Emmelmann, C. (2012) "Investigation of Aging Processes of Ti-6AI-4V Powder Material in Laser Melting" Physics Procedia, 39, pp. 425-431.

https://doi.org/10.1016/i.phpro.2012.10.057

Simchi, A. (2006) "Direct laser sintering of metal powders: Mechanism, kinetics and microstructural features" Materials Science and Engineering: A, 428(1-2), pp. 148-158.

https://doi.org/10.1016/i.msea.2006.04.117

Slotwinski, J. A., Garboczi, E. J., Stutzman, P. E., Ferraris, C. F., Watson, S. S., and Peltz, M. A. (2014) "Characterization of Metal Powders Used for Additive Manufacturing" Journal of research of the National Institute of Standards and Technology, 119, pp. 460-93.

https://doi.org/10.6028/jres.119.018

Spierings, A., Herres, N. and Levy, G. (2011) "Influence of the particle size distribution on surface quality and mechanical properties in AM steel parts" Rapid Prototyping Journal, 17(3), pp. 195-202. https://doi.org/10.1108/13552541111124770

Strondl, A., Lyckfeldt, O., Brodin, H., Ackelid, U. (2015), “Characterization and Control of Powder Properties for Additive Manufacturing" The Journal of Minerals, Metals \& Materials Society, 67 (3), pp 549-554. https://doi.org/10.1007/s11837-015-1304-0

Swift, K.G., Booker, J.D. (2013) “Manufacturing Process Selection Handbook" ButterworthHeinemann, pp. 227-241.

Takemura, S., Koike, R., Kakinuma, Y., Sato, Y. \& Oda, Y. (2019) “Design of powder nozzle for high resource efficiency in directed energy deposition based on computational fluid dynamics simulation" The International Journal of Advanced Manufacturing Technology, pp. 1-15.

https://doi.org/10.1007/s00170-019-03552-1

Tang, Y., Zhou, Y., Hoff, T., Garon, M. and Zhao, Y.F. (2016) “Elastic modulus of 316 stainless steel lattice structure fabricated via binder jetting process" Materials Science and Technology, 32(7), pp. 648-656. https://doi.org/10.1179/1743284715Y.0000000084

Tekna (n.d.) "TekSphero-200 - Plasma Powder Spherodization" [online] Available here: http://www.tekna.com/landing-page/teksphero-200 (Accessed: 1st August 2019)

The Economist (2011) "The printed world" [online] Available here:

https://www.economist.com/briefing/2011/02/10/the-printed-world (Accessed August 23rd, 2019)

Vock, S., Klöden, B., Kirchner, A., Weißgärber, T. and Kieback, B (2019) “Powders for powder bed fusion: a review" Progress in Additive Manufacturing, pp. 1-15. https://doi.org/10.1007/s40964-019$\underline{00078-6}$ 
Wang, F., Williams, S., Colegrove, P. and Antonysamy, A.A. (2012) “Microstructure and Mechanical Properties of Wire and Arc Additive Manufactured Ti-6Al-4V" Metallurgical and Materials

Transactions A, 44(2), pp. 968-977. https://doi.org/10.1007/s11661-012-1444-6

Wang, Y., Shi, J., Lu, S. and Xiao, W. (2017) "Investigation of Porosity and Mechanical Properties of Graphene Nanoplatelets-Reinforced AlSi10 Mg by Selective Laser Melting" Journal of Micro NanoManufacture, 6(1). https://doi.org/10.1115/MSEC2017-2911

Wohlers, T., Campbell, I., Diegel, O., Huff, R. and Kowen, J. (2019) “Wohlers Report 2019: 3D Printing and Additive Manufacturing: State of the Industry" Wohlers Associates

Wycisk, E., Solbach, A., Siddique, S., Herzog, D., Walther, F., and Emmelmann, C. (2014) "Effects of defects in laser additive manufactured Ti-6Al-4V on fatigue properties" Physics Procedia, 56, pp. 371-378. https://doi.org/10.1016/i.phpro.2014.08.120 